\title{
CYCLIC ADENOSINE 3':5'-MONOPHOSPHATE PHOSPHODIESTERASE AND ITS ROLE IN LEARNING IN DROSOPHILA
}

\author{
SANDRA L. SHOTWELL ${ }^{2}$
}

Division of Biology, California Institute of Technology, Pasadena, California 91125

Received August 18, 1982; Revised October 25, 1982; Accepted November 10, 1982

\begin{abstract}
Drosophila carrying the X-linked mutation dunce (dnc) showed poor learning in a negative reinforcement olfactory conditioning paradigm (Dudai, Y., Y. -N. Jan, D. Byers, W. G. Quinn, and S. Benzer (1976) Proc. Natl. Acad. Sci. U. S. A. 73: 1684-1688). More recently, dnc flies were shown to have reduced activity for one of two cAMP phosphodiesterases (PDEs) present in normal flies, PDE II, whereas PDE form I was unaffected (Byers, D., R. L. Davis, and J. A. Kiger, Jr. (1981) Nature 289: 79-81). A micro-assay technique is described that allows the separate measurement of PDE I and PDE II in crude extracts, based on specific inhibition of PDE I [ $\left.{ }^{3} \mathrm{H}\right]$ cAMP hydrolysis by cGMP. Using this technique, PDE II is shown to occur normally at high specific activity in the nervous system, consistent with the hypothesis that this enzyme plays a role in neuronal function. Reduced PDE II activity correlates with poor learning in $d n c$ flies at three developmental stages (first and third instar larva and adult), as well as in response to genetic modification of $d n c$ gene activity. Biochemical and genetic experiments fail to reveal any abnormal regulation of PDE II in $d n c$. The specific activity of PDE II is shown to correlate in a one to one fashion with the level of normal $d n c$ gene $\left(d n c^{+}\right)$activity at five different doses of $d n c^{+}$. These results support the hypothesis that PDE II represents the primary product of the $d n c$ gene, indicating a role for this enzyme in Drosophila learning.
\end{abstract}

Genetic analysis of learning in Drosophila began with the isolation of mutant strains affected in learning or memory. The first such mutant, dunce $(d n c)$, was isolated by Benzer and his co-workers (Dudai et al., 1976) using an olfactory conditioning paradigm (Quinn et al., 1974). In this test, $d n c$ flies showed greatly reduced learning compared with that of controls. The specific sensory and motor abilities required for the learning task appeared normal in $d n c$ flies, suggesting that their poor performance was due to a defect in some mechanism

\footnotetext{
${ }^{1}$ This work was carried out in the laboratory of Seymour Benzer. I am grateful to him for support and advice, to Lawrence Kauvar for introducing me to the project, and to William Agnew and Shinobu Fujita for helpful discussions. I thank Richard Lewis, Andrew Moiseff, Mark Tanouye, Tadmiri Venkatesh, and Lawrence Zipursky for valuable comments on the manuscript, and Carol Shotwell for preparing the figures. This work was supported by National Institutes of Health Grant GM-07616, National Science Foundation Grant PCM 79-11771 to S. Benzer, and funds from the Lawrence A. Hanson Foundation.

${ }^{2}$ Present address: Department of Neurobiology, Sherman Fairchild Science Building, Stanford University School of Medicine, Stanford, CA 94305.
}

underlying neuronal plasticity. Further study by Dudai $(1979,1981)$ and Tempel and Quinn (1980), using different olfactory paradigms, showed that under certain conditions, $d n c$ flies were capable of almost normal learning, but memory decayed very rapidly. This transient ability to demonstrate associative learning suggested that the primary behavioral lesion in $d n c$ is defective short term memory.

Byers et al. (1981) identified a biochemical defect that potentially underlies this short term memory deficit when they found that $d n c$ flies exhibited abnormal regulation of cAMP. They found reduced activity levels for PDE II, one of two cAMP phosphodiesterases (PDEs) found in normal Drosophila. PDE I, which sedimented more rapidly in sucrose gradients, was normal. The enzyme defect in $d n c$ was associated with elevated levels of cAMP. cAMP functions as a second messenger mediating the effects of many hormones and neurotransmitters (Robison et al., 1971; Bloom, 1975; Nathanson, 1977; Greengard, 1980). It is thought to participate in synaptic facilitation, a simple form of nonassociative learning at the cellular level (Brunelli et al., 1976; Castellucci et al., 1980), and it has been implicated in the learning of 
mammals (Sattin, 1981). Thus, it was of great interest to find a defect in cAMP metabolism associated with a known memory mutant in Drosophila.

One major value of these studies lies in the potential ability of this mutation to provide a direct link between PDE II activity and learning. If the normal $d n c$ gene $\left(d n c^{+}\right)$encodes the cAMP-PDE molecule itself, then other phenotypes associated with mutations at the $d n c$ locus must result directly from abnormal PDE II activity (see Fig. 1). If, on the other hand, the $d n c$ gene regulates PDE II activity indirectly, the possibility would remain that learning behavior was altered via some other mechanism also regulated by this gene. Distinguishing between these two possibilities represents an important step toward understanding the role of cAMP in Drosophila learning.

The experiments presented below demonstrate that PDE II activity normally is present in the nervous system and that its reduced activity in response to genetic modifications of $d n c$ gene activity correlates with poor learning. Further studies indicate that $d n c$ mutants have normal regulation of PDE II and that PDE II activity varies in a dose-dependent manner with the number of copies of the $d n c^{+}$gene, indicating that $d n c^{+}$is the structural gene for this enzyme. Additional support for this hypothesis comes from the recent studies of Davis and Kiger (1981) and Kauvar (1982) on abnormalities in the properties of PDE II activity associated with two $d n c$ alleles.

\section{Materials and Methods}

Mutations and chromosome rearrangements. Normal Drosophila melanogaster were from the wild-type stock Canton Special (CS). The mutant alleles $d n c^{1}$ and $d n c^{2}$ were induced in this stock by ethyl methane sulfonate mutagenesis (Dudai et al., 1976; Byers, 1980). The alleles $d n c^{M 11}$ and $d n c^{M 14}$ were induced by the same method in a stock carrying the X-linked visible markers yellow, crossveinless, vermilion and forked (Mohler, 1977). Two deficiency chromosomes $\left[D f(1) N^{71 h 24-5}\right.$, $\left.D f(1) d^{75 e l 9}\right]$ and two duplication chromosomes $\left[D p(1 ; Y) w^{+}, \quad D p(1 ; 2) w^{+5167}\right]$ previously described by

A

B
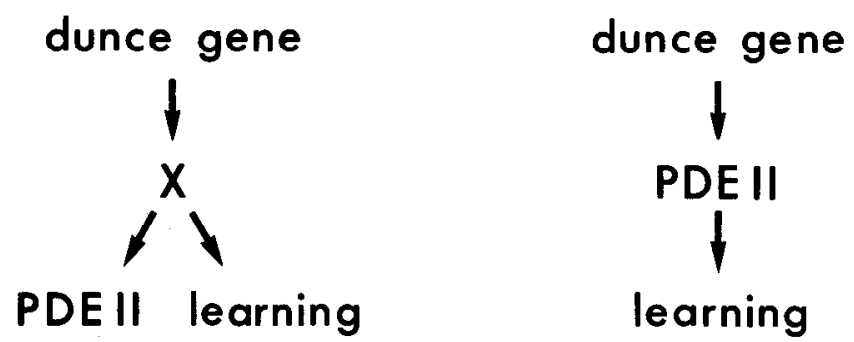

Figure 1. Schematic representation of two possible relationships between the diminished PDE II activity and the learning disability associated with the dnc mutant gene. $A$, A defect in unknown gene product X leads to reduced PDE II activity and to poor learning via separate mechanisms. The connection of PDE II with learning is incidental. $B$, The $d n c$ gene codes directly for PDE II. The learning disability results from this primary defect; PDE II plays a role in learning.
Kiger and Golanty (1977) were used to alter the number of copies of the $d n c^{+}$region of the $\mathrm{X}$ chromosome. The regions duplicated or deleted by these chromosomes are shown in Figure 2.

Behavioral testing. Adult flies (4 to 10 days of age) were tested in the olfactory conditioning paradigm of Quinn et al. (1974). In brief, groups of 20 to 40 flies were presented alternately with two tubes containing different odorants, one of which was paired with electric shock. After three training trials, the flies were presented with fresh tubes bearing the same odorants. Learning was demonstrated by selective avoidance of the tube containing the odor that was previously paired with shock. The learning index $(\Lambda)$ indicates the fraction of flies avoiding the odorant that was previously paired with shock, minus the fraction avoiding the control odor. These experiments were carried out at $20^{\circ} \mathrm{C}$ using 3-octanol $(1 \%)$ and 4methylcyclohexanol $(0.5 \%)$ as odorants.

Sample preparation. First or third instar larvae or etherized 3- to 5-day-old adults were suspended at a concentration of 10 animals $/ \mathrm{ml}$ in 0.2 to $1.0 \mathrm{ml}$ of buffer A (40 mM Tris- $\mathrm{HCl}, \mathrm{pH} 7.5,10 \mathrm{mM} \mathrm{MgCl}_{2}, 1 \mathrm{~mm} \mathrm{CaCl}$, $2 \mathrm{~mm} 2$-mercaptoethanol) and homogenized at $0^{\circ} \mathrm{C}$ by 10 complete strokes with a motorized Teflon/glass homogenizer. An aliquot of each homogenate was stored at $-20^{\circ} \mathrm{C}$ for protein assay. A second aliquot was mixed with $1 / 10$ th volume of buffer A containing $12.5 \mathrm{mg} / \mathrm{ml}$ of bovine serum albumin (BSA) for enzyme assay. For clonal cell line studies, $10^{7}$ cells from flask cultures containing modified Schneider's medium plus $18 \%$ calf serum were pelleted at $200 \times g$ for $5 \mathrm{~min}$, washed in $2 \mathrm{ml}$ of buffer A, pelleted, resuspended in $0.25 \mathrm{ml}$ of buffer A, and homogenized as described above. For tissue distribution studies, tissues from 5 to 10 animals were dissected out in cold isotonic saline solution $(128 \mathrm{~mm} \mathrm{NaCl}, 2 \mathrm{mM}$ $\mathrm{KCl}, 4 \mathrm{mM} \mathrm{MgCl} 2,1.8 \mathrm{mM} \mathrm{CaCl}_{2}, 35.5 \mathrm{~mm}$ sucrose, $5 \mathrm{~mm}$ HEPES, pH 7.1), transferred to $0.2 \mathrm{ml}$ of buffer $\mathrm{A}$, and homogenized as described above.

Protein assay. Protein concentrations were determined using the Bio-Rad dye-binding assay with BSA as the standardizing protein (Bradford, 1976). Samples were assayed in duplicate at protein concentrations in the linear range of the absorbance versus concentration curve.

Ion exchange column chromatography. The sample for DEAE chromatography was prepared by homogenizing $2.2 \mathrm{gm}$ of etherized 4- to 6-day-old $C S$ adults in $10 \mathrm{ml}$ of buffer B (40 mM Tris-HCl, pH 7.5, 0.1 mM EDTA, 100 $\mathrm{mm} \mathrm{NaCl}, 2 \mathrm{~mm} 2$-mercaptoethanol) at $0^{\circ} \mathrm{C}$ using a Brinkman Polytron homogenizer. After centrifugation at $100,000 \times g$ for $1 \mathrm{hr}$, the supernatant was dialyzed against $800 \mathrm{ml}$ of buffer B for $2.5 \mathrm{hr}$ at $4^{\circ} \mathrm{C}$. Six milliliters of dialyzed supernatant were applied to the top of a $30 \times 1$ $\mathrm{cm}$ column of DE52 cellulose (Whatman) equilibrated with buffer B, and the column was washed with $90 \mathrm{ml}$ of buffer $B$. Bound material was eluted with a $90-\mathrm{ml}$ gradient of 100 to $300 \mathrm{~mm} \mathrm{NaCl}$ in buffer B. Two-milliliter fractions were collected into tubes containing $0.22 \mathrm{ml}$ of buffer C (40 mM Tris-HCl, pH 7.5, $100 \mathrm{~mm} \mathrm{MgCl}, 10 \mathrm{~mm}$ $\mathrm{CaCl}_{2}, 2 \mathrm{~mm} 2$-mercaptoethanol, $10 \mathrm{mg} / \mathrm{ml}$ of BSA). The resultant fractions were thus equilibrated in buffer $\mathrm{A}$ containing $1 \mathrm{mg} / \mathrm{ml}$ of BSA.

Cyclic nucleotide phosphodiesterase assay. PDE ac- 


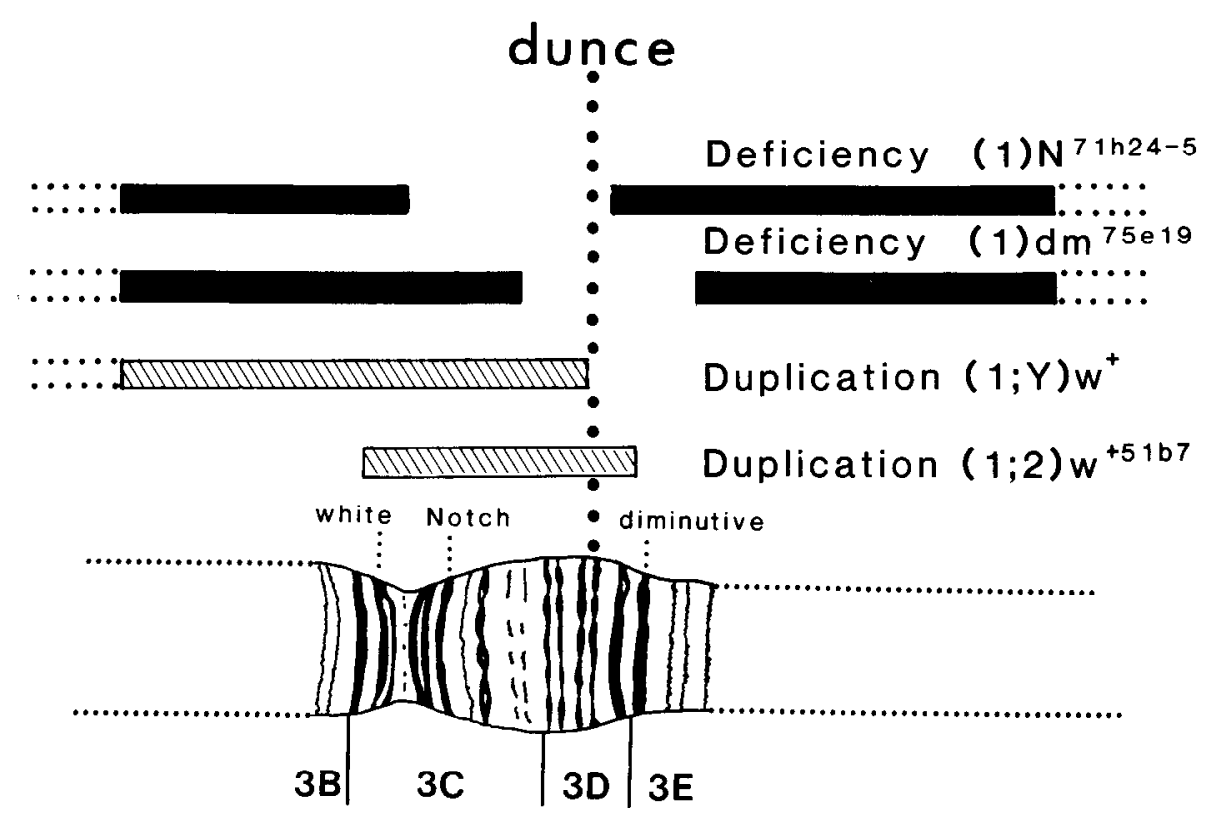

Figure 2. Segment of the Drosophila X chromosome showing the location of deficiency and duplication chromosomes used in genetic studies of the $d n c$ gene. The break points of these chromosomes, as determined by Lefevre (see Kiger and Golanty, 1977), are illustrated in the upper portion of the figure. Solid bars represent deficiency chromosomal material, and hatched bars represent duplication chromosomal material; dotted lines indicate their continuation. Gaps indicate the absence of chromosomal material. The sketched region represents approximately $3 \%$ of the $\mathrm{X}$ chromosome. The locations of the genes white, Notch, and diminutive are shown for reference. Note on terminology: The numbers below the figure represent regions of the $\mathrm{X}$ chromosome as mapped by Bridges (1935). The $\mathrm{X}$ chromosome is divided into 20 regions (numbered 1 to 20 from the distal tip to the centromere), each of which contains five subdivisions (lettered A to F). The meaning of the names assigned to duplication or deficiency chromosomes is best illustrated by an example. Duplication $(1 ; 2) w^{+51 b 7}$ is a chromosome containing duplicated material from the X (1) chromosome translocated into the second (2) chromosome. The duplicated region contains a normal copy of the white gene $\left(w^{+}\right)$. The superscript identifies a specific chromosome.

tivities were assayed using a modification of the procedure of Rangel-Aldao et al. (1978). The reaction was initiated by adding $5 \mu \mathrm{l}$ of buffer A containing $100 \mu \mathrm{M}$ cyclic nucleotide plus $\left[{ }^{3} \mathrm{H}\right]$ cyclic nucleotide (New England Nuclear, 0.4 to $2.0 \mathrm{Ci} / \mathrm{mmol}$ in final reaction mixture) to $20 \mu \mathrm{l}$ of sample at $30^{\circ} \mathrm{C}$, and terminated by adding $10 \mu \mathrm{l}$ of quench solution $(0.2 \mathrm{M}$ EDTA plus $5 \mathrm{mg} /$ $\mathrm{ml}$ each of cAMP, $5^{\prime}$-AMP, and adenosine for cAMPPDE assay, or cGMP, $5^{\prime}$-GMP, and guanosine for cGMPPDE assay). Unhydrolyzed substrate was separated from products by ascending polyethyleneimine thin layer chromatography developed for $20 \mathrm{~min}$ with $50 \mathrm{mM} \mathrm{KCl}$. Nucleotide $3^{\prime}: 5^{\prime}$-monophosphate (cNMP) and $5^{\prime}$-NMP bands were visualized under UV illumination, cut, and placed in separate scintillation vials. The radioactive material was eluted from the bands for $10 \mathrm{~min}$ in $1 \mathrm{ml}$ of $0.7 \mathrm{M} \mathrm{MgCl}_{2}, 20 \mathrm{mM}$ Tris-HCl, $\mathrm{pH}$ 7.5. Ten milliliters of scintillant (Aquasol-2, New England Nuclear) were added to each vial, and radioactivity was determined using a liquid scintillation counter. Blank values were determined using buffer $A$ in place of the enzyme sample. Two millimolar 5'-AMP was included in the reaction to greatly reduce further degradation of the hydrolytic products $\left[{ }^{3} \mathrm{H}\right] 5^{\prime}$-AMP and $\left[{ }^{3} \mathrm{H}\right] 5^{\prime}$-GMP without inhibiting PDE activity. The concentration of cyclic nucleotide in the assay $(20 \mu \mathrm{M})$ was at least 5 times the $K_{m}$ values for PDE I or II reported by Davis and Kiger (1980). Thus the amount of enzyme was rate limiting for hydrolysis. Hydrolysis of $\left[{ }^{3} \mathrm{H}\right]$ cAMP and $\left[{ }^{3} \mathrm{H}\right]$ cGMP was linear from $0 \%$ to at least 30 to $40 \%$ hydrolysis. Hydrolytic activity, in the presence of $1 \mathrm{mg} / \mathrm{ml}$ of BSA, was also linear with dilution and with time of assay up to at least $30 \mathrm{~min}$ at $30^{\circ} \mathrm{C}$.

Separate assay of two enzyme activities in mixture. Davis and Kiger (1980) studied the kinetic properties of PDEs I and II separated by gel filtration. They found that both enzymes had similar affinities for cAMP $\left(K_{m}\right.$ $=4 \mu \mathrm{M}$ for PDE I; $K_{m}=2 \mu \mathrm{M}$ for PDE II). Whereas PDE II was specific for cAMP, PDE I also hydrolyzed cGMP with high affinity $\left(K_{m}=4 \mu \mathrm{M}\right)$, and each PDE I substrate served as a competitive inhibitor for hydrolysis of the other. In theory, this competitive inhibition should allow independent assay of the two cAMP-PDEs, without requiring their physical separation; unlabeled cGMP should inhibit $\left[{ }^{3} \mathrm{H}\right]$ cAMP hydrolysis by PDE I without affecting PDE II activity. This idea was tested by applying it to the assay of separated forms of Drosophila PDE activities. Figure 3 represents a DEAE column fractionation of the soluble PDE activities of normal flies. Assaying fractions with $\left[{ }^{3} \mathbf{H}\right]$ cAMP as substrate revealed two separate peaks of hydrolytic activity. When $\left[{ }^{3} \mathrm{H}\right] \mathrm{cGMP}$ served as substrate, only the first peak contained hydrolytic activity, identifying it as PDE I. Hydrolysis of $\left[{ }^{3} \mathrm{H}\right]$ cAMP by PDE I was inhibited by 3 mM cGMP, whereas the hydrolytic activity of the second peak, PDE II, was unaffected. Thus, in an unfractionated sample, hydrolysis of $\left\lfloor^{3} \mathrm{H}\right] \mathrm{cAMP}$ in the presence of excess cGMP represents PDE II activity, and cAMP hydrolysis that is inhibited by cGMP represents PDE I activity. When applied to the assay of PDEs I and II mixed in known proportions, 


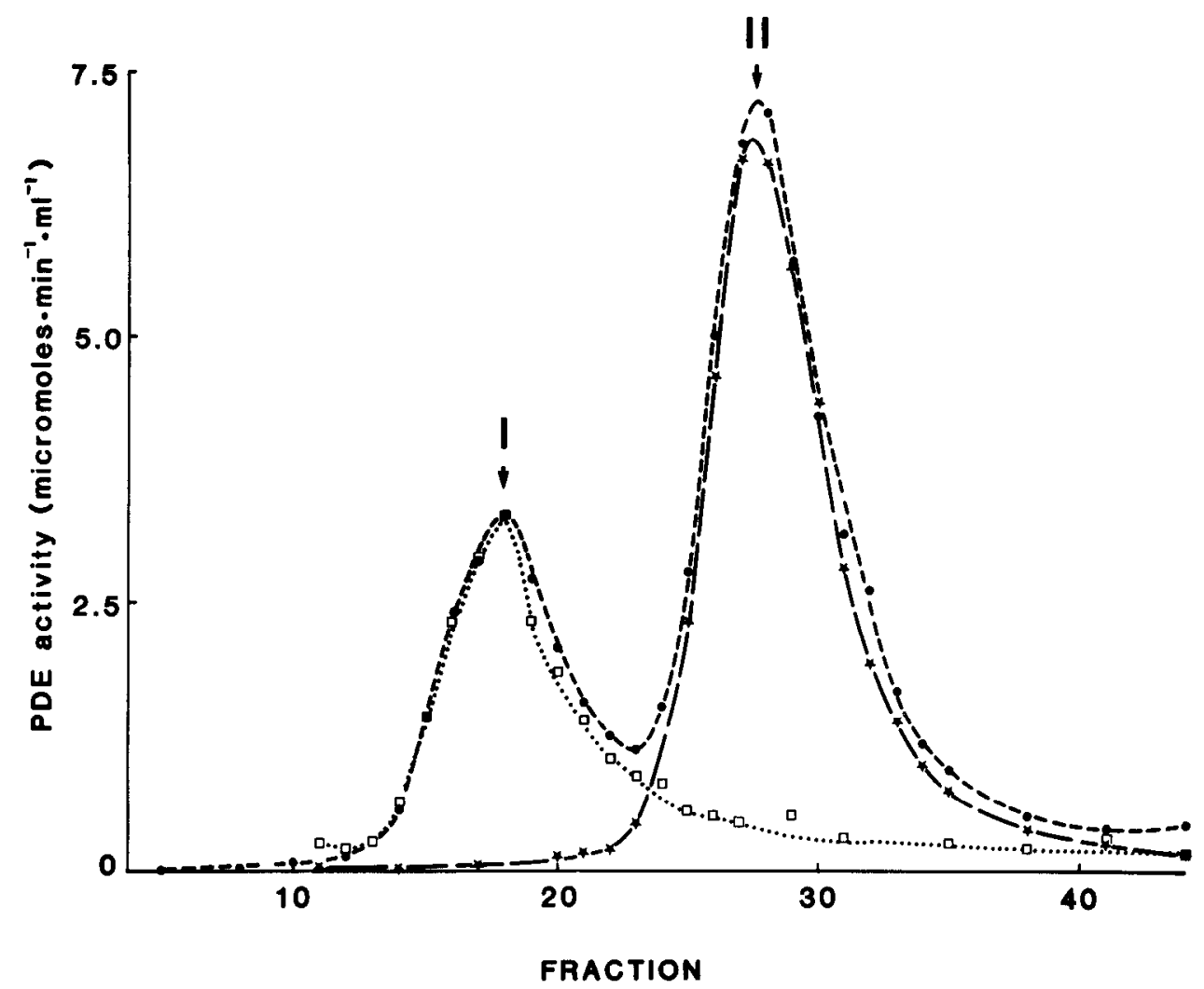

Figure 3. Procedure for separate assay of two cAMP-PDE isozymes. Ion exchange column chromatography of PDE from normal Drosophila yields two peaks of PDE activity eluting in the gradient, one at $170 \mathrm{~mm} \mathrm{NaCl}(I)$ and one at $220 \mathrm{~mm} \mathrm{NaCl}$ (II). The first peak contains hydrolytic activity against both cAMP (solid circles) and cGMP (open squares). Hydrolysis of $\left[{ }^{3} \mathrm{H}\right]$ cAMP by PDE I is eliminated by the inclusion of $3 \mathrm{mM}$ cGMP (stars). PDE II hydrolyzes only cAMP, and its activity is not affected by cGMP. There was no PDE activity in the pregradient fractions (data not shown).

these criteria gave an accurate measure over a 10-fold range of relative $\mathrm{PDE} \mathrm{I} / \mathrm{PDE}$ II activities (data not shown). This procedure allows rapid measurement of the separate PDE activities from a sample as small as onetenth of a fly.

\section{Results}

Tissue and cellular distribution of PDE activities. For PDE II to participate in neuronal events underlying memory, it must be present in the nervous system. Histological studies on cryostat sections of Drosophila had shown high cAMP PDE activity in the brain and thoracic ganglion (Kauvar et al., 1980), but it was not possible to determine what fraction of this activity, if any, was contributed by PDE II. An assay procedure was developed to measure the two cAMP-PDE activities separately when both are present in a homogenate (see "Materials and Methods"). When applied to homogenates of tissues dissected from normal flies, this assay reveals the presence of PDE II in the brain at high specific activity (see Table I). The enzyme is not restricted to the brain, however, nor is it the only PDE activity found there. Both PDE I and PDE II activities occur in each of the tissues or body regions tested. In addition, studies on clonal cell lines established from Drosophila embryos indicate that both PDE activities can be observed in the same cell type (see Table I; Shotwell and Konopka, 1982). Between tissues, enzyme
TABLE I

Phosphodiesterase specific activity in normal fly tissues and clonal cell lines

Sample preparation and enzyme assay were as described under "Materials and Methods." Specific activity is defined as picomoles of substrate hydrolyzed $/ \mathrm{min} / \mathrm{mg}$ of protein at $30^{\circ} \mathrm{C}$. Values represent the mean of duplicate assays from three to five experiments.

\begin{tabular}{llccr}
\hline \multirow{2}{*}{ Sample } & & \multicolumn{3}{c}{ PDE (Substrate) } \\
\cline { 3 - 5 } & & II (cAMP) & I (cAMP) & (cGMP) \\
\hline Female & Whole fly & 1800 & 700 & 1200 \\
& Head & 2900 & 2500 & 6600 \\
& Thorax & 1200 & 110 & 420 \\
& Abdomen & 2000 & 750 & 860 \\
& Brain & 4700 & 3700 & 9300 \\
& Gut & 3400 & 730 & 1200 \\
Male & Ovary & 250 & 200 & 270 \\
& Whole fly & 1900 & 560 & 1400 \\
& Head & 3200 & 2800 & 6900 \\
& Thorax & 2000 & 130 & 510 \\
Clonal cell & Abdomen & 1700 & 630 & 950 \\
lines & CL 7 & 150 & 30 & 120 \\
& CL 12 & 130 & 18 & 160 \\
& CL 14 & 58 & 36 & 84 \\
\hline
\end{tabular}

specific activities vary considerably. Of the tissue homogenates tested here, brain contains the highest concentrations of both PDEs I and II. Between the brain and the least concentrated tissue analyzed, the ovary, PDE activities vary more than 10 -fold. 
Relationship between learning behavior and enzyme activity levels at different developmental stages. As mentioned above, $d n c$ adults fail to learn in the olfactory conditioning paradigm of Quinn et al. (1974). More recently, Aceves-Piña and Quinn (1979) developed a similar learning paradigm for larvae and found that both first and third instar larvae bearing the $d n c^{1}$ allele failed to demonstrate learning. If PDE II activity is responsible for poor learning throughout development, then the enzyme defect should occur in $d n c^{1}$ larvae as well. The experiments presented in Figure 4 show that, as in adult $d n c^{1}$ flies, PDE II activity in $d n c^{1}$ first and third instar larvae is reduced to about one-third of the levels found in normal animals. In contrast, PDE I activity is unaffected. Normal function of the $d n c^{+}$gene apparently is critical for both PDE II activity and learning, from the first instar larva to the adult.

Biochemical and genetic regulation of PDE II activity and learning behavior. Reduced PDE II activity in $d n c$ flies could be due to a mutation affecting the structure of the enzyme itself, or it could result from abnormal regulation of enzyme activity. Such abnormal regulation also might affect the activities of other molecules, which could be the ones responsible for the effect on learning behavior (see Fig. 1). Thus, several experiments were carried out to test for abnormal regulation of PDE II in $d n c$ flies.

Normal and $d n c$ flies were co-homogenized in varying ratios (from 1:4 to 4:1), and the PDE II activity of the cohomogenate was measured (Fig. 5). The level of PDE II activity in the combined samples was dependent only on

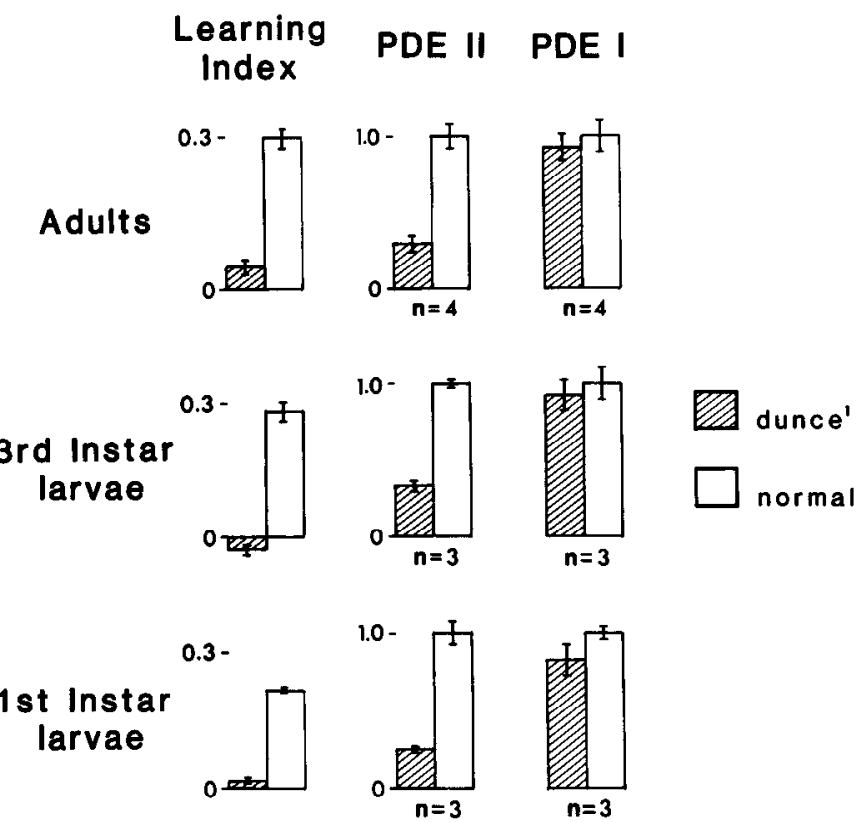

Figure 4. Correlation between reduced PDE II activity and learning disability through development. Left column, Data of Aceves-Piña and Quinn (1979), comparing the learning ability of normal (CS) and $d n c^{1}$ flies at three developmental stages. Middle and right columns, PDE II and PDE I activities, respectively, assayed as described under "Materials and Methods." Duplicate determinations of each PDE activity were averaged and the $d n c$ values normalized to the corresponding $C S$ activity assayed in parallel. Values are presented as mean \pm SEM for $n$ such experiments.

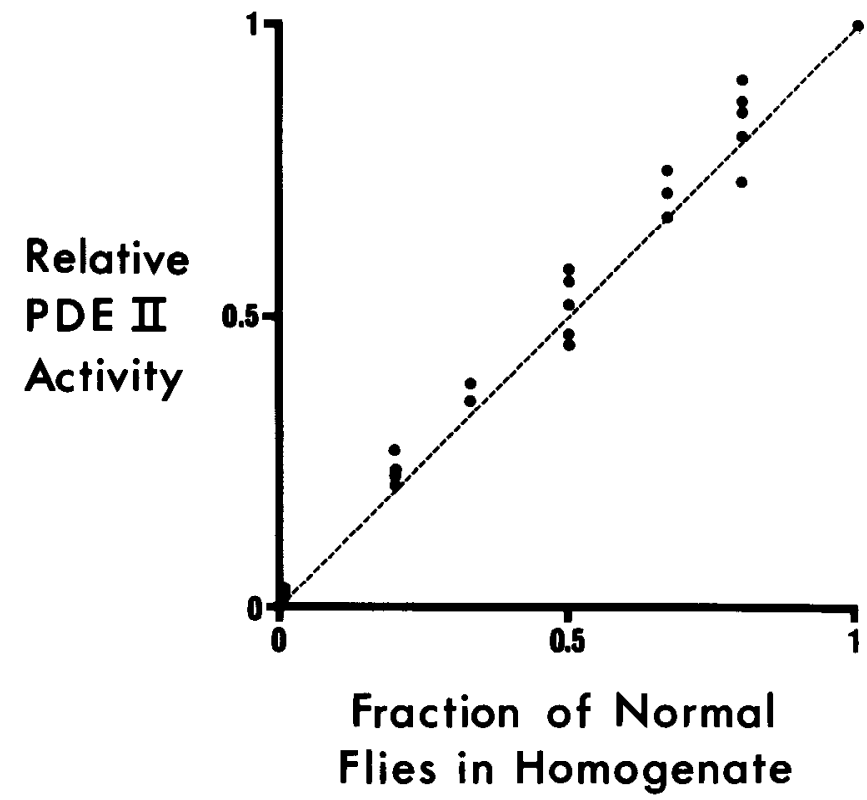

Figure 5. Tests for abnormal biochemical regulation of PDE II activity by co-homogenizing $d n c$ deficiency and normal flies. Flies deficient for $d n c\left[D f(1) N^{71 h 24-5} / D p(1 ; Y) w^{+}\right]$were co-homogenized with normal (CS) flies at one fly $/ 100 \mu \mathrm{l}$ of buffer A. The number of flies of each genotype was varied to yield $C S: d n c$ ratios ranging from $4: 1$ to $1: 4$. The PDE II activity measured in each co-homogenate was normalized to the level of PDE II activity in a $C S$ homogenate assayed in parallel. Each point represents the average of duplicate assays.

the amount of normal fly material present. This indicates that there is no inhibitory substance present in excess in $d n c$ flies that can act to reduce the activity of the normal PDE II enzyme. Nor is there a normally required activator in the control flies capable of rescuing $d n c$ PDE II activity.

The preceding experiment addressed the question of abnormal PDE II regulation at the level of enzyme activity. Further experiments were carried out to test for abnormal genetic regulation. The "point" mutant alleles $d n c^{M 11}$ and $d n c^{M 14}$ completely remove PDE II activity (Davis and Kiger, 1981). A duplication chromosome carrying a normal copy of the $d n c^{+}$gene was introduced into $d n c^{M 11}$ or $d n c^{M 14}$ backgrounds in an attempt to restore genetically the PDE II activity lost through mutation at the $d n c$ locus. The results presented in Figure $6 A$ show that, for both $d n c^{M 11}$ and $d n c^{M 14}$, this genetic manipulation restores PDE II activity to control levels. Thus, when a mutant and a normal copy of the $d n c$ gene are present in the same cell, PDE II activity is the linear sum of the allelic activities, again indicating normal regulation in $d n c$.

Just as a duplication of the $d n c^{+}$gene compensates for reduced PDE II activity in dnc mutants, behavioral experiments show that the duplication also compensates for the learning defect. In the olfactory learning paradigm of Quinn et al. (1974), $d n c^{M 11}$ and $d n c^{M 14}$ achieve low learning indices (Fig. 6B) (Byers, 1980). Introducing a normal copy of $d n c^{+}$into the mutant backgrounds restores learning to the level seen in control flies (Fig. $6 B$ ).

Thus, the results of several biochemical, genetic, and behavioral experiments fail to demonstrate any evidence 

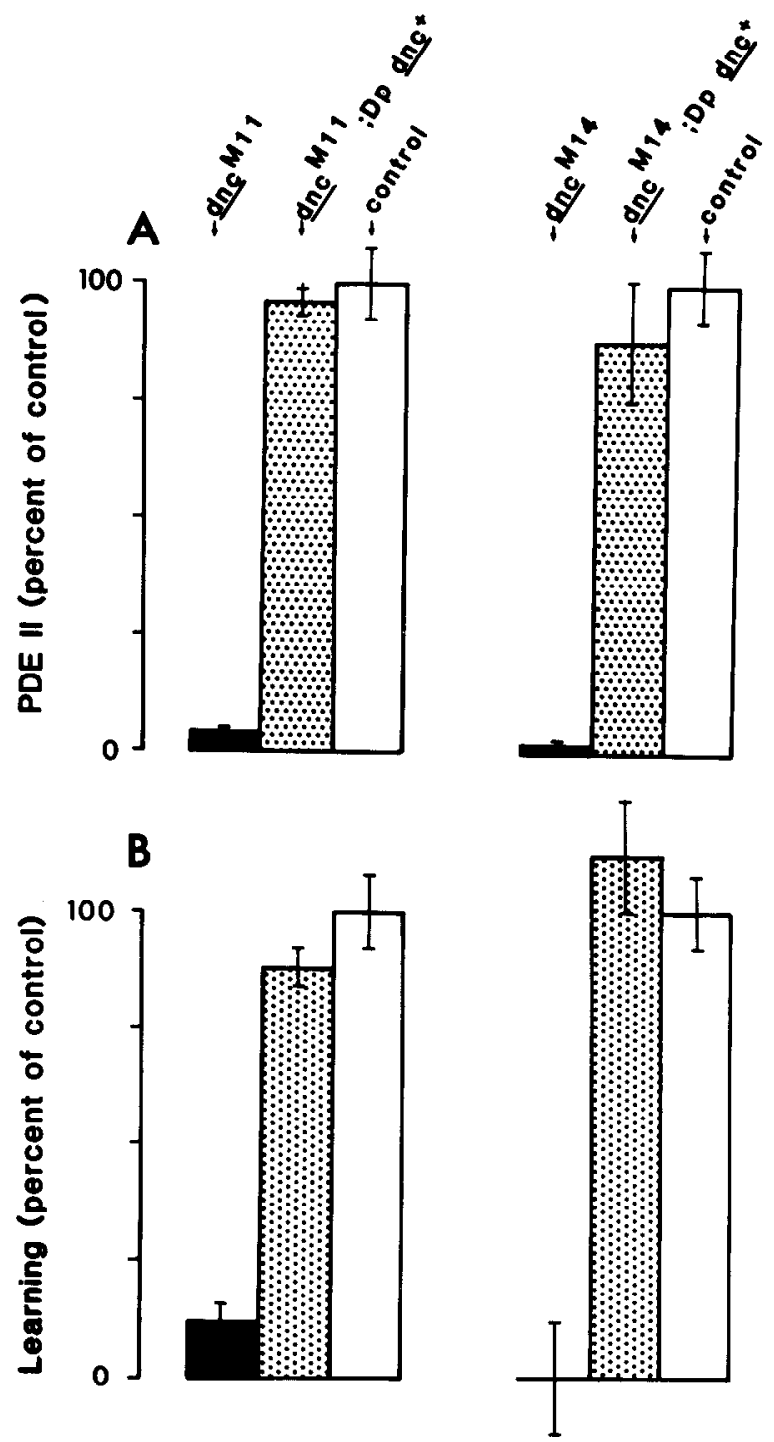

Figure 6. A, Tests for abnormal genelic or biochemical regulation of PDE II activity by adding a duplication of the $d n c^{+}$gene to "point" mutant $d n c$ males. The PDE II activity in homogenates of male flies bearing a $d n c$ mutation $\left(d n c^{M 11}\right.$ or $d n c^{M 14}$ ) was compared with the PDE II activity of control males and mutant males carrying an additional copy of the normal $d n c^{+}$gene $\left[D p(1 ; 2) w^{+51 b 7}\right]$. Three 4 - to 5-day-old males of a given genotype were homogenized in $300 \mu \mathrm{l}$ of buffer $\mathrm{A}$ and assayed for PDE and protein as described under "Materials and Methods." The average of duplicate determinations of PDE II specific activity was normalized to the value obtained for control flies assayed in parallel. Each bar represents the mean \pm SEM for four to six experiments. Both mutant and control flies carried the X-linked markers yellow, crossveinless, vermilion, and forked. $B$, The effect on learning of mutant and normal $d n c$ genes, separately and in combination. Male flies with a "point" $d n c$ mutation $\left(d n c^{M 11}\right.$ or $\left.d n c^{M 14}\right)$ were compared to control males and mutant males carrying an additional copy of the normal $d n c^{+}$gene $\left[D p(1 ; 2) w^{+51 b 7}\right]$. Learning tests were as described under "Materials and Methods." Scores were normalized to those of control flies. Each bar represents the mean \pm SEM of three experiments.

of abnormal regulation of PDE II activity in the $d n c$ mutant. These results are consistent with the hypothesis that the $d n c^{+}$gene encodes the enzyme molecule itself.

Gene dosage analysis. In Drosophila, genes that code
TABLE II

Genotypes of flies with altered $\mathrm{dnc}^{+}$dosage

Flies for $d n c^{+}$gene dosage studies (see Fig. 7) were progeny of single pair backcross matings. The duplication (Dp) and deficiency (Df) chromosomes used are illustrated in Figure 2. + designates a wild-type chromosome. A wild-type $\mathrm{X}$ chromosome carries a copy of $d n c^{+}$; a wildtype second chromosome and a $\mathrm{Y}$ chromosome do not.

\begin{tabular}{clll}
\hline $\begin{array}{c}\text { Effective } \\
\text { Dose of } \\
d n c^{+}\end{array}$ & Sex & \multicolumn{1}{c}{$\begin{array}{c}\text { X Chromosome } \\
\text { Genolype }\end{array}$} & \multicolumn{1}{c}{$\begin{array}{c}\text { Second } \\
\text { Chromosome } \\
\text { Genotype }\end{array}$} \\
\hline 0.0 & Female & $D f(1) N^{75 e 19} / D f(1) N^{71 h 24-5}$ & $+/+$ \\
0.0 & Male & $D f(1) N^{71 h 24-5} / D p(1 ; Y) w^{+}$ & $+/+$ \\
0.5 & Female & $D f(1) N^{75 e 19} /+$ & $+/+$ \\
0.5 & Female & $D f(1) N^{71 h 24-5} /+$ & $+/+$ \\
1.0 & Female & $+/+$ & $+/+$ \\
1.0 & Male & $+/ Y$ & $+/+$ \\
1.5 & Female & $+/+$ & $D p(1 ; 2) w^{+51 b 7} /+$ \\
2.0 & Male & $+/ Y$ & $D p(1 ; 2) w^{+51 b 7} /+$ \\
\hline
\end{tabular}

for enzymes exhibit a strict dosage dependence, i.e., enzyme levels correspond to the number of copies per cell (the dosage) of the normal structural gene for the enzyme. This type of quantitative dosage dependence has been found in all cases where it has been studied for enzymes with a known structural gene. Regulatory genes, on the other hand, do not seem to give quantitative compensation over several doses of the gene. Thus, dosage dependence has come to serve as a diagnostic indicator of a structural gene (O'Brien and MacIntyre, 1978).

PDE activity levels were analyzed in flies with five different effective doses of the normal $d n c$ gene. Duplications and deficiencies for the $d n c$ region of the $\mathrm{X}$ chromosome (see Fig. 2) were used to produce flies with the genotypes listed in Table II. Drosophila females retain two $\mathrm{X}$ chromosomes, each of which is half as active as the single X in a male (see Lucchesi, 1978). Because of this dosage compensation, duplicating a region of the $\mathrm{X}$ chromosome in a female Drosophila yields an animal with $150 \%$ of the normal complement of those genes, whereas a duplication in a male doubles the dose. Similarly, females with one normal chromosome and one deficiency chromosome exhibit 50\% of normal activity levels, whereas males bearing only the deficiency chromosome lack activity for the deleted genes. For this experiment, flies with the equivalent of $0,0.5,1.0,1.5$, and 2.0 times the usual dose of the normal $d n c$ gene were analyzed. For each sample, enzyme activities were normalized to protein content, and the specific activities in flies with abnormal doses of $d n c^{+}$were compared with those of normal siblings of the same sex assayed in parallel.

The results presented in Figure 7 show that cGMP hydrolysis and cAMP hydrolysis by PDE I are unaffected by alterations in the dose of the $d n c^{+}$gene, indicating that this region does not contain the structural gene(s) for these enzyme activities. In contrast, PDE II activity varies linearly with the dose of the $d n c^{+}$gene. Thus, at five different doses of the $d n c^{+}$gene, PDE II activity corresponds closely to the number of copies of the gene, as would be expected if this were the structural gene for the enzyme.

\section{Discussion}

Multiple forms of enzymes catalyzing the same reaction have been seen in many species and for numerous 
C AMP-PDE II

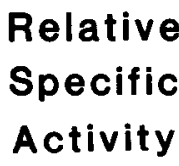

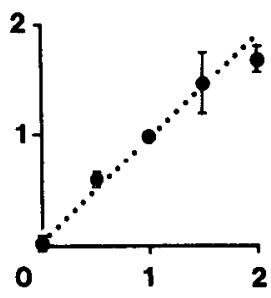

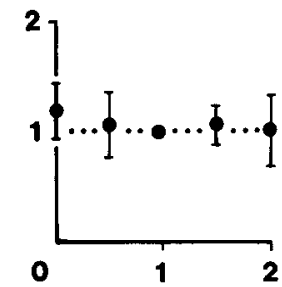

cGMP -PDE

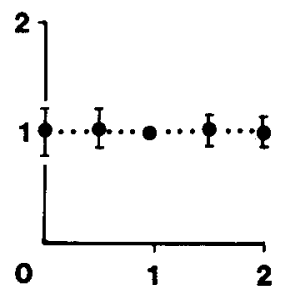

\section{Effective dose of the normal dunce gene}

Figure 7. The effect on enzyme activity of varying the dose of the $d n c^{+}$gene. Gene activity in Drosophila is dosage compensated, with each $\mathrm{X}$ chromosome in a female cell being half as active as the single $\mathrm{X}$ chromosome in a male cell. Thus, adding or deleting a region of the $\mathrm{X}$ chromosome in a female alters the dose of the affected genes by a factor of 0.5 , and in a male by a factor of 1.0 . Duplication and deletion chromosomes used to alter the $d n c^{+}$region of the $\mathrm{X}$ chromosome are diagramed in Figure 2 . Genotypes used are presented in Table II. Sibling flies of the same genotype and age (3 to 5 days) were homogenized in groups of two or three and assayed in duplicate, as described under "Materials and Methods." PDE specific activities were compared to those of control siblings (dose of $d n c^{+}=1.0$ ) assayed in parallel. The results are presented as the mean \pm SEM for $n$ experiments. $n=13$ for dose $=0.0 . n=18$ for dose $=0.5$. $n=7$ for doses 1.5 and 2.0. The dashed lines indicate the PDE activity levels expected if dosage effects are strictly linear and $d n c^{+}$encodes PDE II. PDE II activity is proportional to the dose of $d n c^{+}$; PDE I activity is unaffected.

enzyme systems, including PDE (O'Brien and MacIntyre, 1978; Strada and Thompson, 1978). Perhaps the most striking observation is that flies completely lacking one of the enzyme activities, PDE II, can exist at all. If PDE II normally performs vital functions, PDE I must at least partially compensate for them in the $d n c$ mutant. The ubiquitous presence of PDEs I and II in varying proportions in Drosophila tissues suggests that their regulation of cAMP levels may affect different cellular functions in different tissues. The poor learning and female sterility (Byers et al., 1981; Salz et al., 1982) of $d n c$ flies indicate that PDE II normally plays a role in these functions. If PDE I also participates, its activity alone is not sufficient for normal learning or female fertility. Thus, the $d n c$ mutant provides evidence for functional separation of cAMP phosphodiesterase isozymes in Drosophila.

In other systems, PDE activities are regulated by calmodulin, a heat-stable, $\mathrm{Ca}^{2+}$-dependent protein that also regulates several other enzyme activities (for review, see Klee et al., 1980). Yamanaka and Kelly (1981) provided strong evidence for the existence of a calmodulinlike substance in Drosophila, but the heat-stable PDE they found it to regulate corresponds to PDE I (Kauvar, 1982), which seems normal in $d n c$ flies. Thus, calmodulin itself did not seem a likely suspect in our investigation of the $d n c$ defect. The possibility remained that another regulatory substance affected PDE II in Drosophila. However, the experiments presented here provide biochemical and genetic evidence that $d n c$ flies have normal regulation of PDE II activity, indicating that abnormal regulation is not the cause of the enzymatic defect in dnc.

Several technical considerations previously made it difficult to draw firm conclusions as to the sensitivity of PDEs I and II to the dosage of $d n c^{+}$. Kiger and Golanty (1977) identified what later proved to be the $d n c$ gene as a region affecting the level of activity of cAMP-PDE. In their original screen, they assayed for total cAMP-PDE hydrolytic activity, which presumably represents the summed activities of PDEs I and II. As they suggested, this is the most likely explanation for their finding that female flies carrying only one copy of this region had about $70 \%$ of normal cAMP-PDE activity, rather than the value of $50 \%$ expected for the activity of the gene's product. Assay of homogenates utilizing the different thermolabilities and $\mathrm{Mg}^{2+}$ dependence of the two PDEs (Kiger and Golanty, 1979) provided only qualitative evidence that one or both activities were present. Physical separation of the soluble PDE activities from males or females deficient for the $d n c$ region demonstrated that PDE II activity was greatly reduced in these flies (Kiger and Golanty, 1979; Davis and Kiger, 1981). However, in both studies PDE I activity also seemed to be reduced with respect to controls. In addition, quantitative analysis based on physical separation of soluble PDE activities was difficult due to potential trapping of activity in the $100,000 \times g$ pellet, or losses during fractionation, where reported recoveries varied from $49 \%$ to $113 \%$ (Davis and Kiger, 1981). Thus, it was important to test the dosage sensitivities of both PDEs using the method reported here, which permits separate, quantitative assay of the PDE isozyme activities in unfractionated homogenates. The present analysis covers five doses of the normal $d n c$ gene, providing a more extensive test of dosage sensitivity. In addition to demonstrating a close correlation between PDE II activity and the dose of $d n c^{+}$, the data show that levels of cGMP hydrolysis and cAMP hydrolysis by PDE I are not altered by variations in the dose of this region of the chromosome. A recently characterized cGMP-specific PDE (Kauvar, 1982) also is not sensitive to the dosage of $d n c^{+}$(data not shown). Thus, these results provide a quantitative demonstration of the strict dependence of PDE II activity on the dose of the $d n c^{+}$ gene.

At four of the $d n c^{+}$doses studied $(0,0.5,1.0,1.5)$, PDE II activity quantitatively reflects $d n c^{+}$gene activity. In the fifth case, a male bearing a duplication for $d n c^{+}$and, therefore, carrying an effective dose of 2.0 , the PDE II value is $167 \pm 5 \%$ (mean $\pm \mathrm{SEM}$ ). Although this is slightly lower than the expected value of $200 \%$, such a result is common for duplication-bearing males. Similar studies of activity levels in males bearing duplications for 
the structural gene of three other proteins gave values of $129 \%$ (G6PD), 135\% (6PGD), and 163\% (Sgs-4) (see Stewart and Merriam, 1980). There seems to be some other factor that becomes limiting as the dose of the structural gene is increased.

Further biochemical evidence in support of the hypothesis that $d n c^{+}$encodes PDE II comes from the work of Davis and Kiger (1981), who studied the kinetic properties of PDE II fractionated by gel filtration from supernatants of $d n c^{2}$ and normal flies. They found anomalous kinetic plots for $d n c^{2}$ PDE II reproducibly under two different experimental conditions and suggested that the anomalous kinetics resulted from mutation in the dnc gene. Kauvar (1982) also found altered kinetics for PDE II in $d n c^{2}$ homogenates. In addition, he has observed abnormal thermolability in the PDE II activity of $d n c^{l}$ homogenates, as well as in the partially purified enzyme. Both altered kinetics and increased thermolability are often interpreted as evidence for an amino acid substitution that results in reduced stability of the protein's tertiary structure. Although these altered properties of PDE II activity in the mutants could result from abnormal post-translational modification, that seems unlikely in the light of the evidence presented here that regulation of PDE II activity seems normal in $d n c$ flies. In addition, homogenates of $d n c^{1} /$ wild-type heterozygotes show both mutant and normal PDE II thermolabilities (Kauvar, 1982), again suggesting that the defect is not regulatory but intrinsic to the enzyme molecule.

In conclusion, these studies provide both genetic and biochemical evidence that $d n c^{+}$encodes PDE II, indicating that the defective short term memory of the $d n c$ mutant results from abnormal regulation of cAMP. In neuronal systems, cAMP regulates the phosphorylation of specific proteins by cAMP-dependent protein kinases (Greengard, 1980). It seems to participate in several electrophysiological functions, including presynaptic facilitation (Brunelli et al., 1976; Castelluci et al., 1980), the generation of repetitive firing (Kaczmarek et al., 1978), and the inhibition of rhythmic bursting (Drummond et al., 1980).

The genetic demonstration that cAMP metabolism plays a critical role in Drosophila learning is consistent with findings correlating cAMP metabolism with learning in other systems (see introduction). The learning behavior of the $d n c$ mutant further demonstrates that, in Drosophila, regulation of cAMP levels by PDE II is not necessary for the initial events of learning but plays a key role in the intermediate stage of short term memory formation. This places cAMP metabolism in the middle of the chain of events leading from experience to long term changes in neuronal function. The next link in the chain is presumably phosphorylation of one or more specific proteins. The $d n c$ mutant provides an excellent system in which to study the identity, location, and function of these phosphorylated proteins whose regulation may critically affect memory.

\section{References}

Aceves-Piña, E. D., and W. G. Quinn (1979) Learning in normal and mutant Drosophila larvae. Science 206: 93-96.

Bloom, F. E. (1975) The role of cyclic nucleotides in central synaptic function. Rev. Physiol. Biochem. Pharmacol. 74: 1103.

Bradford, N. (1976) A rapid and sensitive method for the quantitation of microgram quantities of protein utilizing the principle of protein dye binding. Anal. Biochem. 72: 248-254.

Bridges, C. B. (1935) Salivary chromosome maps. J. Hered. 26: 60-64.

Brunelli, M., V. Castellucci, and E. R. Kandel (1976) Synaptic facilitation and behavioral sensitization in Aplysia: Possible role of serotonin and cyclic AMP. Science 194: 1178-1181.

Byers, D. (1980) Studies on learning and cyclic AMP phosphodiesterase of the dunce mulant of Drosophila melanogaster. Ph.D. Thesis, California Institute of Technology, Pasadena.

Byers, D., R. L. Davis, and J. A. Kiger, Jr. (1981) Defect in cyclic AMP phosphodiesterase due to the dunce mutation of learning in Drosophila melanogaster. Nature 289: 79-81.

Castellucci, V. F., E. R. Kandel, J. H. Schwartz, F. D. Wilson, A. C. Nairn, and P. Greengard (1980) Intracellular injection of the catalytic subunit of cyclic AMP-dependent protein kinase simulates synaptic facilitation of transmitter release underlying behavioral sensitization in Aplysia. Proc. Natl. Acad. Sci. U. S. A. 77: 7492-7496.

Davis, R. L., and J. A. Kiger (1980) A partial characterization of the cyclic nucleotide phosphodiesterases of Drosophila melanogaster. Arch. Biochem. Biophys. 203: 412-421.

Davis, R. L., and J. A. Kiger (1981) dunce mutants of Drosophila melanogaster: Mutants defective in the cycle AMP phosphodiesterase enzyme system. J. Cell Biol. 90: 101-107.

Drummond, A. H., J. A. Benson, and I. B. Levitan (1980) Serotonin-induced hyperpolarization of an identified Aplysia neuron mediated by cyclic AMP. Proc. Natl. Acad. Sci. U. S. A. 77: 5013-5017.

Dudai, Y. (1979) Behavioral plasticity in a Drosophila mutant, dunce $^{\mathrm{DB} 276}$. J. Comp. Physiol. 130: 217-275.

Dudai, Y. (1981) Olfactory choice behavior of normal and mutant Drosophila in a conflict situation in a successive conditioning paradigm. Soc. Neurosci. Abstr. 7: 643.

Dudai, Y., Y. -N. Jan, D. Byers, W. G. Quinn, and S. Benzer (1976) dunce, a mutant of Drosophila deficient in learning. Proc. Natl. Acad. Sci. U. S. A. 73: 1684-1688.

Greengard, P. (1980) Intracellular signals in the brain. Harvey Lect. 75: 277-331.

Kaczmarek, L. K., K. Jennings, and F. Strumwasser (1978) Neurotransmitter modulation, phosphodiesterase inhibitor effects, and cyclic AMP correlates of afterdischarge in peptidergic neurites. Proc. Natl. Acad. Sci. U. S. A. 75: 52005204.

Kauvar, L. M. (1982) Defective cyclic adenosine $3^{\prime}: 5^{\prime}$-monophosphate phosphodiesterase in the Drosophila memory mutant dunce. J. Neurosci. 2: 1347-1358.

Kauvar, L. M., S. L. Shotwell, S. C. Fujita, S. Benzer, R. Pierantoni, and D. C. Spurr (1980) The dunce mutant and cAMP phosphodiesterase. Calif. Inst. Tech. Biol. Annu. Rep., pp. 155-156.

Kiger, J. A., Jr., and E. Golanty (1977) A cytogenic analysis of cyclic nucleotide phosphodiesterase activities in Drosophila. Genetics 85: 609-622.

Kiger, J. A., Jr., and E. Golanty (1979) A genetically distinct form of cyclic AMP phosphodiesterase associated with chromomere 3D4 in Drosophila melanngaster. Genetics 91: 521535 .

Klee, C. B., T. H. Crouch, and P. G. Richman (1980) Calmodulin. Annu. Rev. Biochem. 49: 489-515.

Lucchesi, J. C. (1978) Gene dosage compensation and the evolution of sex chromosomes. Science 202: 711-716.

Mohler, J. D. (1977) Developmental genetics of the Drosophila egg: Identification of 59 sex-linked cistrons with maternal effects on embryonic development. Genetics 85: 259-272.

Nathanson, J. A. (1977) Cyclic nucleotides and nervous system 
function. Physiol. Rev. 57: 157-256.

O'Brien, S. J., and MacIntyre, R. J. (1978) Genetics and biochemistry of enzymes and specific proteins of Drosophila. In The Genetics and Biology of Drosophila, M. Ashburner and T. Wright, eds., Vol. 2a, pp. 395-551, Academic Press, London.

Quimn, W. G., W. A. Harris, and S. Benzer (1974) Conditioned behavior in Drosophila melanogaster. Proc. Natl. Acad. Sci. U. S. A. 71: 708-712.

Rangel-Aldao, R., D. Schwartz, and C. S. Rubin (1978) Rapid assay for cyclic AMP and cyclic GMP phosphodiesterases. Anal. Biochem. 87: 367-375.

Robison, A., R. Butcher, and E. Sutherland (1971) Cyclic AMP, Academic Press, New York.

Salz, H. K., R. L. Davis, and J. A. Kiger, Jr. (1982) Genetic analysis of chromosome 3D4: The dunce and sperm-amotile genes in Drosophila. Genetics 100: 587-596.

Sattin, A. (1981) Genetic determination of cyclic AMP level in brain: Some behavioral implications. In Neuropharmacology of Central Nervous System and Behavioral Disorders: Physiologic and Pharmacologic Bases of Drug Therapy, G. C. Palmer, ed., pp. 197-210, Academic Press, New York.

Shotwell, S. L., and R. Konopka (1982) Hormonal regulation of cyclic nucleotide phosphodiesterase activity in clonal Drosophila cell lines. Calif. Inst. Tech. Biol. Annu. Rep., p. 164.

Stewart, B., and J. Merriam (1980) Dosage compensation. In The Genetics and Biology of Drosophila, M. Ashburner and T. Wright, eds., Vol. 2d, pp. 107-140, Academic Press, London.

Strada, S. J., and W. J. Thompson (1978) Multiple forms of cyclic nucleotide phosphodiesterases: Anomalies or biologic regulators? Adv. Cyclic Nucleotide Res. 9: 265-283.

Tempel, B. L., and W. G. Quinn (1980) Reward learning in Drosophila melanogaster. Soc. Neurosci. Abstr. 6: 589.

Yamanaka, M. K., and L. E. Kelly (1981) A calcium/calmodulin-dependent cyclic adenosine monophosphate phosphodiesterase from Drosophila heads. Biochim. Biophys. Acta 674: $277-286$. 